\title{
International Journal of Geriatric Psychiatry
}

\section{The Dementia Early Stage Cognitive Aids New Trial (DESCANT) intervention: a} goal attainment scaling approach to promote self-management

\section{Short running title: Goal attainment scaling in DESCANT intervention}

Helen Chester*, Rebecca Beresford, Paul Clarkson, Charlotte Entwistle, Vincent Gillan, Jane Hughes, Martin Orrell, Rosa Pitts, Ian Russell, Eileen Symonds, David Challis, and Members of the HoSt-D (Home Support in Dementia) Programme Management Group

*corresponding author

Helen Chester

Institute of Mental Health

The University of Nottingham

School of Medicine

Jubilee Campus

University of Nottingham Innovation Park

Triumph Road

Nottingham

NG7 2TU

helen.chester@nottingham.ac.uk

Rebecca Beresford

School of Health Sciences

Faculty of Biology, Medicine and Health

The University of Manchester

Ellen Wilkinson Building

Manchester

M15 6JA

rebecca.beresford@manchester.ac.uk

Paul Clarkson

School of Health Sciences

Faculty of Biology, Medicine and Health

The University of Manchester

Ellen Wilkinson Building

Manchester

M15 6JA

paul.clarkson@manchester.ac.uk 
Charlotte Entwistle

Department of Psychology

Lancaster University

Fylde College

Lancaster

LA1 4YF

c.entwistle1@lancaster.ac.uk

Vincent Gillan

Formerly of

School of Health Sciences

Faculty of Biology, Medicine and Health

The University of Manchester

Ellen Wilkinson Building

Manchester

M15 6JA

vincent.gillan@manchester.ac.uk

Jane Hughes

Institute of Mental Health

The University of Nottingham

Jubilee Campus

University of Nottingham Innovation Park

Triumph Road,

Nottingham

NG7 2TU

jane.hughes@nottingham.ac.uk

Martin Orrell

Institute of Mental Health

The University of Nottingham

Jubilee Campus

University of Nottingham Innovation Park

Triumph Road,

Nottingham

NG7 2TU

m.orrell@nottingham.ac.uk

Rosa Pitts

Division of Health Research

Faculty of Health and Medicine

Lancaster University

Bailrigg

Lancaster

LA1 4YG

r.pitts1@lancaster.ac.uk 
Ian Russell

Swansea Trials Unit

Medical School

Swansea University

Swansea

Wales

SA2 8PP

i.t.russell@swansea.ac.uk

Eileen Symonds

Institute of Mental Health

The University of Nottingham

School of Medicine

Jubilee Campus

University of Nottingham Innovation Park

Triumph Road

Nottingham

NG7 2TU

Esym105248@aol.com

David Challis

Institute of Mental Health

The University of Nottingham

Jubilee Campus

University of Nottingham Innovation Park

Triumph Road,

Nottingham

NG7 2TU

david.challis@nottingham.ac.uk

\section{Acknowledgements}

The DESCANT research team acknowledges the support of the NIHR Clinical Research Network. Other members of the Programme Management Group were: Reagan Blyth (Pennine Care NHS Foundation Trust), Professor Linda Davies (University of Manchester), Dr David Jolley, Professor Narinder Kapur (University College London), Professor Fiona Poland (University of East Anglia), Professor Brenda Roe (Edge Hill University), Professor Chris Roberts and Jean Tottie (Together in Dementia Everyday). The team would also like to thank Professor Bob Woods and Professor Aimee Spector for their assistance in developing the manual used for the DESCANT intervention; and Professor Brenda Roe and Dr Mark Wilberforce for their respective contributions to the training of interviewers who collected the baseline data reported in this paper.

\section{Funding}

This study was funded by the National Institute for Health Research (NIHR) Programme Grants for Applied Research (reference number: DTC-RP-PG-0311-12003). The views expressed are those of the authors and not necessarily those of the NIHR or the Department of Health and Social Care. 
Data availability statement: Research data are not shared.

Conflicts of interest: The authors declare no potential conflict of interest.

Author contributions: All authors were involved in the design and conduct of the study; the collection, analysis, and interpretation of data; in the preparation of the manuscript; and in the review or approval of the manuscript. 


\section{Abstract}

Objectives: This paper investigated goals identified by people with dementia and their carers to promote the self-management of symptoms and abilities; measured achievement using goal attainment scaling (GAS); and explored the reflections of Dementia Support Practitioners (DSPs) facilitating it.

Methods and design: Within this pragmatic randomised trial DSPs gave memory aids, training and support to people with mild to moderate dementia and their carers at home. Data were collected across seven NHS Trusts in England and Wales (20162018) and abstracted from intervention records and semi-structured interviews with DSPs delivering the intervention, supplemented by a subset of the trial dataset. Measures were created to permit quantification and descriptive analysis and interview data thematically analysed. A GAS measure for this intervention in this client group was derived.

Results: Engagement was high across the 117 participants and 293 goals were identified. These reflected individual circumstances and needs; and enabled classification and assessment of their attainment. Seventeen goal types were identified across six domains: self-care; household tasks; daily occupation; orientation; communication; and well-being and safety. On average participants achieved nominally significant improvement regarding the specified goals of 1.4 with standard deviation of 0.6. Five interviews suggested that DSPs' experiences of goal setting were also positive.

Conclusions: GAS is useful for assessing psychosocial interventions for people with early-stage dementia. It has a utility in identifying goals, promoting self-management and providing a personalised outcome measure. There is a strong case for exploring whether these clear benefits translate to other interventions in other populations in other places.

Keywords: early stage dementia; goal attainment scaling; goal setting and attainment; memory aids; randomised controlled trial; self-management

\section{Key points:}

- Dementia Support Practitioners in discussion with people with mild to moderate dementia and their carers identified personal goals associated with a memoryfocused intervention and assessed attainment of those goals, thereby promoting self-management.

- Application of a coding framework developed by the research team enabled classification and quantification of progress towards individual goals.

- Goal attainment was assessed for each participant creating an aggregate measure from individual scores to assess average attainment

- Modest changes (positive and negative) in people with mild to moderate dementia with carers were captured by Goal Attainment Scaling 


\section{Introduction}

Dementia is an international challenge; worldwide there were an estimated 47 million people living with dementia in 2015, projected to reach 130 million in $2050 .{ }^{1}$ In 2019 there were approximately 885,000 older people with dementia in the United Kingdom (UK) with over $40 \%$ having mild to moderate dementia. ${ }^{2}$ Two-thirds of people with dementia live in the community and an estimated 670,000 people in the UK act as their primary carers. ${ }^{3}$ Many people with dementia find it difficult to manage their day to day cognitive problems. Employing techniques to help them and their family carers to manage day to day problems and difficulties can help to improve functioning and quality of life $e^{4,5}$ and may reduce stigma, prolong or maintain relationships and independence.

At the heart of enhancing self-management is equipping people to cope with the challenges of their condition such as, the maintenance or creation of meaningful life roles and managing its emotional consequences. ${ }^{6}$ Whilst self-management for people with dementia is considered to have been a neglected area for research, there is some evidence that it may be beneficial, particularly in the early stages of the condition. $6,7,8$ Five core features of this are: problem solving (including defining the problem and generating possible solutions); acquiring appropriate knowledge to inform decision making in response to changes in the disease condition; support in sourcing and utilising resources; formation of a partnership between the individual and health care professional to make informed choices about their care; and making and undertaking a realistic plan of action. ${ }^{6,9}$ Another aspect of self-management is self-tailoring, whereby the individual plays an active role in choosing their intervention. ${ }^{6,9}$ Both the features and approach are reflected in this trial in which Goal Attainment Scaling 
(GAS) was used both to tailor a personalised memory-focused intervention to the specific needs and goals of people with dementia and their carers by promoting selfmanagement and to assess attainment following its delivery.

Kiresuk and Sherman developed GAS for programme evaluation in community mental health services. ${ }^{10}$ It is an outcome measure incorporating the needs and circumstances of patients, permitting both personalisation of goals and comparison of attainment between patients through the application of a standard scoring system and summary formula. ${ }^{11,12,13}$ GAS is valuable for patients for whom 'modest improvements in health or functional status may be clinically important goals' (p.111). ${ }^{12}$ It has been used internationally ${ }^{11,14-16}$ for a range of patient groups including mild cognitive impairment ${ }^{14}$ and dementia ${ }^{15-17}$ and in a variety of settings. ${ }^{18-25}$ Studies have varied in size from small ${ }^{14}$ to larger studies. ${ }^{26}$ As GAS was considered a highly responsive tool, modest sample sizes have been considered sufficient to test the efficacy of an intervention. ${ }^{13}$ Such studies require care: creating, using and coding the data collection tool; training interviewers; judging when to assess attainment; and how to engage patients and carers. ${ }^{13,25,27} \mathrm{~A}$ review ${ }^{13}$ confirmed the feasibility of engaging people with dementia and their carers in setting their own goals as did a subsequent study ${ }^{28}$ which successfully used self-reported goal attainment as a primary outcome measure. This was the approach adopted in this study. It sought to investigate the use of GAS to assist people with early dementia who experienced problems in relation to memory in their daily lives using self-management techniques. 


\section{Method}

The aim of this paper is threefold to: investigate the goals identified by people with dementia and their carers to promote the self-management of symptoms and abilities; measure achievement using the goal attainment process; and explore the reflections of Dementia Support Practitioners (DSPs) facilitating it. This was part of the Dementia Early Stage Cognitive Aids New Trial (DESCANT) trial described in detail elsewhere. ${ }^{29}$ An overview is provided below.

\section{Setting}

This trial was a multi-site pragmatic randomised trial to design and implement an intervention to improve the cognitive abilities, function and well-being of people with early-stage dementia and their carers by providing a range of memory aids, and training and support in their use; and to evaluate its effectiveness and costeffectiveness. It was a four-week intervention delivered in the participants home by DSPs involving the provision of assistive technology and support to people with dementia and their carers to address issues of concern they had about their memory in their everyday life. Examples of help provided included day-date clocks, whiteboards and bespoke items. Participants were people with mild to moderate dementia who had an identified carer, defined as the primary person responsible for supporting them. DESCANT took place in ten NHS Trusts - nine in England and one in Wales. Ethical approval was obtained from the National Research Ethics Service (NRES) (15/NW/0822). The effectiveness and cost-effectiveness of the intervention was assessed through a randomised controlled trial ${ }^{29}$; and its implementation by 
process evaluation. ${ }^{30} \mathrm{~A}$ specially convened subgroup, including an experienced occupational therapist, oversaw the process evaluation and the development, implementation and reporting of this GAS. This paper focuses on participants allocated to the intervention group who participated in GAS. Data were obtained from three sources: the GAS exercise; semi-structured interviews with DSPs as part of the wider process evaluation ${ }^{30}$; and the main trial dataset.

\section{Recruitment}

There were eight eligibility criteria for the main trial (aged 50 years or older; under care of one of the trial memory clinics; within one year of first attendance; have mild to moderate dementia; capable of giving informed consent; able to engage with the intervention; have a carer; and be living at home at baseline). Participants had to meet the eligibility criteria for the main trial, been randomised to receive the DESCANT intervention and allocated to the intervention group, and have participated in a baseline interview.

\section{Data collection}

A worksheet was developed for administration in participants' homes as part of an intervention record with an accompanying manual providing guidance on completion. ${ }^{31}$ It was informed by previous work ${ }^{13,19,24}$ and developed by a team which included researchers, a clinical psychologist, an experienced service manager and a DSP. Further guidance on completion was provided to DSPs through researcher-led training sessions prior to data collection. 
The GAS worksheet was completed by the DSP with the person with dementia and their carer. Given the personalised nature of the intervention it was anticipated that inputs and support required would vary with individual needs and circumstances. In the first week, participants identified areas where they were experiencing difficulties with memory and specified up to three goals they would like to achieve by the fourth week using a tailored package of memory aids and strategies. At both times participants were asked to estimate their perceived level of attainment (examples in Figure 1). 
Figure 1 Goal attainment - illustrative scores

\begin{tabular}{|c|c|c|c|c|}
\hline & \multicolumn{4}{|c|}{ Examples of goals } \\
\hline Level of attainment & Goal 1: Medication & $\begin{array}{c}\text { Goal 2: Handling } \\
\text { telephone messages }\end{array}$ & $\begin{array}{c}\text { Goal 3: Daily } \\
\text { routine/appointments }\end{array}$ & Goal 4: Shopping \\
\hline $\begin{array}{c}\text { Week 1: Current } \\
\text { "Where I am" } \\
\text { (Baseline score=0) }\end{array}$ & $\begin{array}{l}\text { Has difficulty } \\
\text { remembering to take } \\
\text { medication daily }\end{array}$ & $\begin{array}{l}\text { Often forgets details of } \\
\text { telephone messages } \\
\text { resulting in confusion and } \\
\text { missed appointments }\end{array}$ & $\begin{array}{l}\text { Completely reliant on } \\
\text { carer to manage daily } \\
\text { routine and } \\
\text { appointments. }\end{array}$ & $\begin{array}{l}\text { Goes to local shop and } \\
\text { will often forget to buy } \\
\text { some items. }\end{array}$ \\
\hline $\begin{array}{l}\text { Week 1: Planned } \\
\text { "Where I want to be" } \\
(\text { Goal = 2) }\end{array}$ & $\begin{array}{c}\text { To be able to remember } \\
\text { to take medication }\end{array}$ & $\begin{array}{l}\text { Able to independently } \\
\text { manage telephone } \\
\text { messages and } \\
\text { associated tasks. }\end{array}$ & $\begin{array}{l}\text { Require some assistance } \\
\text { to recall appointments } \\
\text { and daily schedule. }\end{array}$ & $\begin{array}{c}\text { Goes to local shop with a } \\
\text { list and usually } \\
\text { remembers to buy all } \\
\text { items. }\end{array}$ \\
\hline $\begin{array}{l}\text { Week 1: Achieved } \\
\text { "Where I am now" }\end{array}$ & $\begin{array}{l}\text { Medication now being } \\
\text { given by carers }\end{array}$ & $\begin{array}{l}\text { Often forgets details of } \\
\text { telephone messages. }\end{array}$ & $\begin{array}{c}\text { Requires a lot of } \\
\text { assistance to recall } \\
\text { appointments and daily } \\
\text { schedule. Anxiety } \\
\text { appears less. }\end{array}$ & $\begin{array}{l}\text { Has been to local shop } \\
\text { and used a list to buy all } \\
\text { that was needed }\end{array}$ \\
\hline & $\begin{array}{l}\text { Much worse than } \\
\text { baseline (=-2) }\end{array}$ & $\begin{array}{c}\text { Maintained baseline } \\
\text { state }(=0)\end{array}$ & $\begin{array}{c}\text { Somewhat better than } \\
\text { baseline }(=1)\end{array}$ & Goal achieved (=2) \\
\hline
\end{tabular}

Source: DESCANT intervention records.

†Coding scheme: Much worse than baseline $=-2$; Somewhat worse than baseline $=-1$;

Maintained baseline state $=0$; Somewhat better than baseline $=1$; Goal achieved $=2$.

There were no examples in the data of ' -1 somewhat worse than baseline'. 
Recruitment for the trial began in November 2016; 126 GAS worksheets completed and returned by 30th November 2018 were included. The cut-off date for GAS and the concurrent process evaluation ensured completion of both before outcome analysis. ${ }^{32}$ Seven trial sites who had recruited most participants in the trial were included in the data collection (the last three sites to start recruitment were excluded). Demographic characteristics and Standardised Mini-Mental State Examination scores ${ }^{33}$ of the 126 participants were extracted from the trial baseline dataset.

Additionally, between May and November 2018 six experienced DSPs from four sites who had completed at least five interventions were invited to take part in a semistructured interview. All but the DSP who left the Trust before interviews were scheduled did so. Within these five interviews DSPs described their experiences of GAS.

\section{Creation of Measures}

Identification of goal types

DSPs' written narrative on the GAS worksheet (Figure 1) were analysed using both inductive and deductive approaches to identify common goal types. ${ }^{34}$ Researchers (HC, RP, VG) based the initial coding frame on the first completed 59 worksheets and refined it to focus on Activities of Daily Living (ADLs) and Instrumental Activities of Daily Living (IADLs). ${ }^{35-37}$ This ensured focus on the goal type rather than the means of achieving it. VG and RP independently applied the resulting coding frame of five domains (self-care; household tasks; daily occupation; orientation; and 
communication) to the data, reviewed by HC. A sixth domain (well-being and safety) emerged from this analysis.

Calculation of goal attainment scale scores

Data from the worksheets were extracted and converted into GAS scores using the study-specific coding scheme in Figure 2, which fulfilled several key requirements. Firstly, this scheme was appropriate to the study population - people with dementia and their carers. The progressive nature of the condition makes it important to identify decline or improvement regarding the specified goals. ${ }^{13}$ Secondly, the scheme was responsive enough to identify subtle changes due to a modest intervention. ${ }^{29}$ Both criteria are reflected in the coding scheme anchored at zero, representing the participant's status before the intervention (Figure 2). Thirdly, the scheme recognised that participants have differing numbers of goals by computing a composite score. Fourthly, the study-specific coding scheme reflected the pragmatic implementation of GAS in this study, notably by not weighting goals. Thus this approach generated a personal measure of attainment for each respondent with at least one goal scored and comparison of attainment across participants. 
Figure 2 Calculation of participants' and mean goal attainment scores

1) Coding attainment of individual participant goals $(1,2$ or 3$)$ from documentation provided by dementia support practitioner into numerical score

-2 Much worse than baseline;

-1 Somewhat worse than baseline

0 Maintained baseline state

1 Somewhat better than baseline

2 Goal achieved

2) Calculation of summary score for each participant: sum of scores for each goal divided by number of goals (e.g. $(2+2+1) / 3=1.67)$.

Sum of participant scores for individual goals $1-3$

Number of goals scored for individual participant

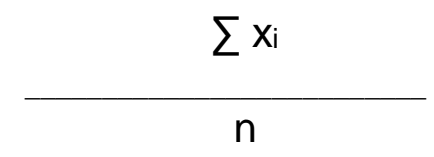

Where $x_{i}=$ numerical value $(-2$ to +2$)$ of the attainment level of the $\mathrm{i}^{\text {th }}$ goal $n=$ number of goals scored

3) Estimation of mean attainment from average of participant scores

Sum of all participants summary GAS scores $\sum x_{i}$

Number of participants with summary scores $\mathrm{n}$

Where $\mathrm{xi}=$ numerical value $(-2$ to +2$)$ of the GAS score of $\mathrm{i}^{\text {th }}$ participant. $\mathrm{n}=$ number of participants

Figure 1 also illustrates the process by which attainment was coded. From the written information, two members of the research team (VG and RP) independently calculated GAS scores for each participant. If that information was not sufficiently detailed, they reviewed data from other sections of the intervention manual. When their scores differed, they consulted a third researcher $(\mathrm{HC})$. There were no instances where agreement was not possible, despite goal attainment being sometimes unclear. 


\section{Data analysis}

Data from the intervention records, including goal type, attainment and GAS scores, were entered into SPSS (version 23) and demographic information from the main trial was added. Frequency counts, mean and standard deviations were used to describe those receiving the intervention and findings from the GAS. Digital recordings of the DSP interviews were professionally transcribed, and data was abstracted for this analysis, focussing on the GAS. Two researchers (HC, CE) used an inductive approach $^{34}$ to code these data, and two $(\mathrm{HC}, \mathrm{JH})$ reviewed these and identified salient themes.

\section{Results}

Table 1 reports the demographic characteristics of 128 participating pairs. Two withdrew before the intervention began, one for lack of time and the other because the person with dementia declined in health. Of the remaining pairs, 117 (93\%) completed all or some of the GAS exercise; eight were described by the DSP as unable to set goals for lack of understanding of the task; and one chose not to engage. 
Table 1: Participant characteristics

$$
\mathrm{n} \text { (out of 128) } \quad \%
$$

\begin{tabular}{|c|c|c|}
\hline \multicolumn{3}{|l|}{ Ethnicity } \\
\hline White & 114 & 89 \\
\hline Asian or Asian British & 9 & 7 \\
\hline Black or African or Caribbean or Black & 5 & 4 \\
\hline \multicolumn{3}{|l|}{ British } \\
\hline \multicolumn{3}{|l|}{ Gender } \\
\hline Male & 58 & 45 \\
\hline Female & 70 & 55 \\
\hline Living with carer & 76 & 59 \\
\hline \multicolumn{3}{|l|}{ Relationship of carer to person with dementia } \\
\hline Spouse or partner & 65 & 51 \\
\hline Son or daughter & 49 & 38 \\
\hline Other relative & 9 & 7 \\
\hline \multirow[t]{2}{*}{ Friend or other } & 5 & 4 \\
\hline & $\begin{array}{c}\text { Mean (Standard } \\
\text { Deviation) }\end{array}$ & Range \\
\hline Age (years) & $79.3(6.3)$ & $64-97$ \\
\hline S-MMSE† score $(n=126)$ & $22.9(5.2)$ & $4-30$ \\
\hline
\end{tabular}

Source: Baseline interview schedules.

†Standardised Mini-Mental State Examination. ${ }^{33}$ 


\section{Participant goals}

With guidance from the DSP the 117 responding pairs identified a total of 293 goals (Table 2). From these, 17 goal types were identified across the six domains. The most frequently occurring goal types were orientation - in locating items (256-87\%) and in time (148-51\%); and maintaining independence $(119-41 \%)$. A single goal could generate more than one type if it addressed both the process and the provision of an aid. For example, where participants required a calendar or clock to orientate themselves, locating this might generate a second goal type. 
Table 2: Goal types - illustrative examples and frequency $(n=293)$

Goal type $†$

\section{Self-care:}

Food and drink preparation

Personal care (dressing, hygiene, teeth, bath and shower, toileting)

Medication management

\section{Household tasks:}

Handling finances

Housework and gardening

Shopping

\section{Daily occupation:}

Hobbies/social life (including TV programmes)

\section{Orientation:}

Orientation- time (day, week, year)

Orientation - person (location of self or carer)

Orientation - place (inside the home)

Orientation - place (outside the home)

Orientation - items (location and movement)

\section{Communication:}

Managing correspondence (telephone, computer, post)

Verbal communication (conveying

information; supporting conversation)

Well-being and safety:

Maintain independence (reliance on carer, appointment management, decision making) Manage mood (reduce anxiety/frustration)

Safety (within and outside the home)

\section{Example}

Remember steps independently to make a cup of coffee

Independently find clean underwear when needed.

Take medication independently with no lapses.

Organise weekly finances with carer

Put things away in the correct place in the kitchen

Take a list to local shop and remember to buy all listed items

Increase frequency of visiting friends and family and participating in leisure activities (such as shopping)

Less confused about the time of day and date

Remember where spouse is and the time when they will arrive home

Locate different rooms within the home

Use a memory strategy when in the community to remember the time to be home

Locate important items easily (such as keys, purse, mobile telephone) on leaving home

Remember telephone calls and messages

Remember telephone number and postcode

Increase independence in managing appointments and activities (reducing

reliance on carer)

Remember basic things and be less agitated

Remember to shut the front door

$\%$

4

31




\section{Goal attainment}

Table 3 summarises the goals specified at week 1 and scored at week 4; and the resulting goal attainment. Most participants (55\%) identified three goals at week 1 and $50 \%$ scored three goals at week 4 . Six pairs did not score any goals; two withdrew partway through the intervention and four had insufficient information. For another 11 it was possible to score some but not all their goals (see footnote to Table 3 for details). Thus, attainment was assessed for 266 (91\%) of 293 goals and a score was estimated for $111(95 \%)$ of 117 pairs who participated. The mean GAS score of 1.4 with standard deviation of 0.6 and possible range between -2 and 2 strongly suggests that participants improved against their chosen goals. 
Table 3: Goal Attainment Scores

n \%†

Number of goals specified (week 1) $(n=117)$

One 7

6

Two

45

39

Three

64

55

Four

Number of goals scored (week 4) $(n=111)$

One

13

Two

42

Three

55

50

Four

1

1

Goal Attainment (goal level analysis) $(n=111)$

Goal achieved

Somewhat better than baseline

59

Maintained baseline state

49

18

Much worse than baseline

1

0

Total number of goals scored $\ddagger$

266

Mean (Min, Max)

St. Dev

Average score

$1.4(-0.5,2.0)$

0.60

†Rounded percentages may not add exactly to 100 per cent.

$\ddagger 27$ out of the 293 goals specified across the 117 participants could not be scored, owing either to missing or unclear information (affecting 21 goals for participants remaining in the study) or to participants withdrawing (affecting 6 goals for two participants). 


\section{Dementia support practitioner reflections}

DSPs provided insights into their experience of GAS. Three broad themes emerged from analysis of these data: co-production; goal setting; and measuring attainment. Figure 3 illustrates these findings with typical quotes. 
Figure 3 Illustrative comments from Dementia Support Practitioners

\begin{tabular}{|c|c|}
\hline Theme & uotation \\
\hline $\begin{array}{l}\text { Co- } \\
\text { production }\end{array}$ & $\begin{array}{l}\text { "quite often you've got shared goals.... on a number of occasions...it might not be actually a goal that the person with dementia has identified } \\
\text { because they might not actually have any but the carer has....And sometimes actually the carers are quite heavily involved in... taking on quite a } \\
\text { few tasks... Part of the dementia process of compensating for dysfunction can sometimes make it difficult for the person with dementia...to be } \\
\text { able to recognise their level of loss of function... person-centred goals are great when somebody is able to, but they are not always appropriate } \\
\text { or applicable" (DSP 1, Quote 1). } \\
\text { "You want to have something tangible at the end. And the way we can look at that, is to give some goals over the next couple of weeks...as long } \\
\text { as you explain it, and put it into context, from when you're having that first conversation, and you can almost pick up whether they're going to } \\
\text { understand the word, goal, or whether you want to use, actions, or sort of where they're coming from. I find carers understand goal, but I find the } \\
\text { person with dementia, it's usually more about what their action's going to be, what they're going to do to help...I find using layman's terms a lot } \\
\text { easier." (DSP 3, Quote 2) }\end{array}$ \\
\hline Goal s & $\begin{array}{l}\text { "The scenarios where it's been a lot more difficult to get your initial goal...is when people haven't had particularly insight into their level of loss of } \\
\text { function... Or where the carer's have taken over an awful lot of the tasks... getting a goal in that situation can be quite challenging.....Sometimes } \\
\text { the lack of a specific answer to a question makes me suspect...that there may be some covering up. So because it's not appropriate to } \\
\text { challenge that directly what l've done is put like a DSP goal of orientation and management of appointments and l've provided them with a } \\
\text { day/date clock" (DSP 1, Quote 3). } \\
\text { "If you're working with people who don't have any insight or who don't believe they've got any difficulties, then asking them to set a goal isn't } \\
\text { going to work. Sometimes you have to use the approach of going through the memory aids and doing it that way, rather than going through the } \\
\text { questionnaire and completing the goals...Another visit...was much more straightforward. We set some goals and then looked at the memory } \\
\text { aids and looked at where they were going to go in the house" (DSP 2, Quote 4). }\end{array}$ \\
\hline & $\begin{array}{l}\text { "If you've been able to get your initial goals, then the goal attainment is quite straightforward. If you've got a situation with your baseline } \\
\text { assessment where it's actually difficult to identify areas, then your evaluation is a lot harder.....it does come down to how well you've been able to } \\
\text { manage to get your goals set in the beginning" (DSP 1, Quote 5). } \\
\text { "It does feel like when you're going back over four weeks, they are saying, oh it's been great... So, you do have to fish it a little bit more. So, well } \\
\text { how's it been, how's it been good? What has it done for you?" (DSP 4, Quote 6). } \\
\text { "Because you do your goal setting and your assessments and your goal settings, so I suppose it does follow very well really with an OT background. } \\
\text { Sometimes I just have struggled with the goals and I think having a little bit of maybe reflection, a reflective time in between the assessments and } \\
\text { then maybe setting the goals or organising...the items might have been helpful" (DSP 5, Quote 7). }\end{array}$ \\
\hline
\end{tabular}


The extent to which goals were shared or co-produced varied according to the insight of the people with dementia into their difficulties, and the level of carer support with everyday tasks (Figure 3, Quote 1). For example, if the carer was providing a lot of support, goals focused on reducing their caring load within the 'maintain independence' type of goal. Explaining the context and the reason for setting goals aided understanding and thus facilitated the task. DSPs perceived that carers were more comfortable with the concept of 'goal' and found this easier than did the person they were caring for. They also reported it helpful to focus on the practical actions required to achieve the goal rather than the goal per se ('what rather than why' (Figure 3, Quote 2). Thus it was sometimes a challenge to distinguish between the process and the provision of the aid when identifying goal types. One DSP reported that it had been helpful leaving yellow cards with goals written on them as a visual reminder throughout the intervention (DSP 3). Another reported the value of repeating the goals throughout the session to aid memory and understanding (DSP 5).

DSPs also reported circumstances where setting goals was challenging, including when the person with dementia appeared to have: minimal needs; lack of insight into their loss of function; or reluctance to report or address areas of difficulty (Figure 3, Quote 3). These also included pairs where the carer provided a lot of support or had taken over tasks, with the result that there was no desire for, or possibility of, the person with dementia resuming responsibility or independence. Setting goals and identifying memory aids was sometimes, but not always, a sequential process, as agreeing on the memory aids to be used was often helpful in setting goals (DSPs 2 and 5). This was especially true where the person with dementia had limited insight or believed that they were not experiencing difficulties (Figure 3, Quote 4). 
DSPs viewed measuring goal attainment as straightforward (DSPs 1 and 3), confirming data in Table 3. The ease with which this was possible was influenced by how well goals had been defined at the outset and it thus proved more difficult if it had been challenging to identify goals initially (Figure 3, Quote 5). DSPs often had to get participants to elaborate on answers to obtain an accurate picture of attainment (Figure 3, Quote 6). DSPs were generally positive about the experience of goal setting, and they reported a good fit between this and their professional skills (DSPS 3 and 5). However, they would also have liked to have more time for reflection between identifying and setting goals (Figure 3, Quote 7).

\section{Discussion}

This study sought to describe the Goal Attainment Scaling (GAS) used within DESCANT; to report the types of goals identified by people with dementia and their carers and subsequent attainment; and to explore the reflections of DSPs on the process. This was achieved by analysing data from the GAS exercise and semistructured interviews with DSPs. Following the DESCANT intervention clear improvement towards goals established at baseline were reported for most participants. This strongly suggests that they perceived that the intervention was effective, consistent with findings from the process evaluation. ${ }^{30}$ Achievement of a specific goal might, for example, positively impact on the domain of self-care, and also promote independence (thereby reducing reliance on the carer) and an improvement in mood. This concurs with other studies which have reported the potential of psychosocial interventions to improve cognition and psychosocial functioning, reduce 
behavioural and psychosocial symptoms of dementia, improve carers' quality of life, and reduce care burden. $., 5,28,38-44$

This study had four limitations. First, the time for data collection was constrained by the need to complete the process evaluation before the main trial analysis. Therefore, only seven of the ten trial sites were included. However, these included the three that recruited most participants. Secondly, the worksheets and manual were developed by the multi-disciplinary research team. In retrospect there would have been value in public involvement in this process. Thirdly, the information on goal attainment was recorded by the DSP delivering the intervention, and therefore open to observer bias due to their interest in the intervention. ${ }^{45-47}$ Researchers sought to minimise this by emphasising to DSPs the importance of accurate recording. Fourthly, no comparisons of GAS scores by demographic characteristics are presented in this paper. However, in respect of ethnicity, numbers did not permit meaningful analysis. Fifthly, the qualitative data also reflected the DSPs' perspective. The research team judged it too demanding to ask people with dementia and their carers to add process data to the four-week intervention and multiple research interviews.

\section{Goal setting and attainment}

The DSPs undertook these activities with the person with dementia and their carer using a study-specific tool (Figure 1). This contrasts with other studies in which participants completed separate GAS assessments. ${ }^{11,12,17,18,20,24}$ The commitment to close collaboration between patient, carer and professionals ${ }^{16,25,26}$ ensured that goal-setting reflected individual needs and circumstances; both participants and DSPs valued this approach. ${ }^{13,30}$ The nature of, and the timeframe for, the DESCANT 
intervention and its evaluation meant that goals were modest. Nevertheless, this study confirmed that GAS is feasible in the context of a psychosocial intervention for people with mild to moderate dementia to identify and measure the attainment of, personalised goals of care and promote greater self-management in activities associated with their lifestyle. ${ }^{6,15}$

\section{Scoring}

There is debate how to compute and analyse GAS scores. Ruble et al. ${ }^{48}$ advocated statistical analysis of raw data because they reflect an underlying continuous distribution. In choosing this approach it was recognised that dementia is a progressive multi-domain disorder, characterised by interference with daily life activities, differing between individuals. ${ }^{13}$ Therefore, a scoring system was adopted capable of confirming maintenance of the status quo and detecting small improvements from baseline. The goals that emerged in analysis focused on ADLs and IADLs for people with dementia, with potential to also benefit carers (see 'maintain independence' for example in Table 2). The emergence of a well-being domain attests to the personalised nature of eliciting goals and scaling them which might be used alongside more standardised measures of patient outcome. More generally, there is evidence that getting the package of support right for people with dementia is beneficial to the well-being of their carers. ${ }^{49}$

\section{Fidelity}

In this study fidelity is defined as 'the extent to which delivery of an intervention adheres to the protocol ... originally developed' (p.315). ${ }^{47}$ This is important because DSPs sought to tailor support to the individual circumstances of participants with 
dementia and their carers whilst ensuring delivery of its core components. ${ }^{30,} 50$ To further promote fidelity worksheets were designed for DSPs to collect data to permit the research team to identify goal types ${ }^{51}$ and calculate GAS scores. A coding scheme (framework) was developed to allow data from the worksheets to be systematically extracted. These measures represented an attempt to ensure that 'as data travels from the point of origination to consumption, it retains its granularity and meaning'. 52 The objectivity inherent in this process may also have acted to counter the potential bias of collecting data in the participant's home environment. Moreover, external researchers were responsible for the analysis. The resulting worksheets confirm that the DSPs were indeed using memory aids to pursue the goals of participants and their carers; and the GAS scores have confirmed that they perceived subsequent progress towards those goals. Though conscious that the resulting data are not totally objective, it was judged that the DSPs kept faith with the manual for the DESCANT intervention.

\section{Conclusion}

Goal attainment scaling for people with dementia and their carers has utility as a means, both of tailoring the delivery of a personalised intervention to promote selfmanagement and of assessing subsequent attainment. Furthermore, it was both feasible and useful in the context of this multi-site pragmatic randomised trial. The resulting goals reflected the needs and circumstances of participants and were well defined, permitting both categorisation between types and assessment as to whether participants attained those goals. The GAS measure appeared responsive to modest improvements in functional status and suggested that participants perceived that the intervention had had a positive effect. Thus, this study also indicated the value of GAS 
as a personalised measure of the efficacy of the intervention. There is a strong case for exploring whether these clear benefits translate to other interventions in other populations in other places. 


\section{References}

1. Alzheimer's Disease International. World Alzheimer Report The Global Impact of Dementia. In Prince M, Wimo A, Guerchet M, Ali G-C, Wu, Y-T, Prina M. (eds) An analysis of prevalence incidence, cost and trends. London: Alzheimer's Disease International; 2015.

2. Wittenberg R, Hu B, Barraza-Araiza L, Rehill A. Projections of older people with dementia and costs of dementia care in the United Kingdom, 2019-2040. London: Care Policy and Evaluation Centre, London School of Economics; 2019.

3. Alzheimer's Society. Dementia 2014: opportunity for change. London: Alzheimer's Society; 2014a.

4. Graff MJ, Vernooij-Dassen MJ, Thijssen M, Dekker J, Hoefnagels WH, Rikkert, MGO. Community based occupational therapy for patients with dementia and their caregivers: randomised controlled trial. BMJ. 2006; 333 (7580): 1196-1199.

5. Orrell M, Aguirre E, Spector A, Hoare Z, Woods RT, Streater A, Donovan H, Hoe J, Russell I. Maintenance Cognitive Stimulation Therapy (CST) for dementia: singleblind, multicentre, pragmatic randomized controlled trial. Br. J. Psychiatry. 2014; 204 (6): 1-8.

6. Mountain G. Self-management for people with early stage dementia: an exploration of concepts and supporting evidence. Dementia. 2006; 5(3): 429-446. 
7. Quinn C, Toms G, Jones C, Brand A, Edwards R, Sanders F, Clare L. A pilot randomized controlled trial of a self-management group intervention for people with early-stage dementia (The SMART study). Int Psychogeriatr. 2016; 28 (5), 787-800.

8. Mountain G. Self-management programme for people with dementia and their spouses demonstrates some benefits, but the model has limitations. Evid Based Nurs. 2017; 20 (1): 26-27.

9. Lorig K, Holman H. Self-management education: History, Definition, Outcomes, and Mechanisms. Ann Behav Med. 2003; 26 (1): 1-7.

10. Kiresuk T, Sherman R. Goal Attainment Scaling: A General Method for Evaluating Comprehensive Community Mental Health Programs. Community Ment. Health J. 1968; 4 (6): 443-453.

11. Rockwood K, Stolee P, Fox R. Use of Goal Attainment Scaling in Measuring Clinically Important Change in the Frail Elderly. J Clin Epidemiol. 1993; 46 (10): 11131118.

12. Hartman D, Borrie M, Davison E, Stolee P. Use of Goal Attainment Scaling in a Dementia Special Care Unit. Am J Alzheimer's Dis. 1997; May/June: 111-115.

13. Bouwens S, van Heugten C, Verhey F. Review of Goal Attainment Scaling as a useful outcome measure in psychogeriatric patients with cognitive disorders. Dement Geriatr Cogn Disord. 2008; 26, 528-540. 
14. O'Sullivan M, Coen R, O'Hora D, Shiel A. Cognitive rehabilitation for mild cognitive impairment: developing and piloting an intervention. Aging Neuropsychol Cogn. 2015; 22 (3): $280-300$.

15. Jennings L, Ramirez K, Hays R, Wenger N, Reuben D. Personalised goal attainment in dementia care: measuring what persons with dementia and their caregivers want. JAGS. 2018; 66: 2120-2127.

16. Dutzi I, Schwenk M, Kirchner M, Bauer J, Hauer K. What would you like to achieve? Goal-setting in patients with dementia in geriatric rehabilitation. BMC Geriatr. 2019; 19 (280): 1-15.

17. Rockwood K, Graham J, Fay S. Goal Setting and Attainment in Alzheimer's Disease Patients Treated with Donepezil. J Neurol Neurosurg Psychiatry. 2002; 73: 500-507.

18. Rockwood K, Howlett S, Stadnyk K, Carver D, Powell C, Stolee P. Responsiveness of Goal Attainment Scaling in a Randomised Controlled Trial of Comprehensive Geriatric Assessment. J Clin Epidemiol. 2003; 56: 736-743.

19. Stolee P, Rockwood K, Fox R, Streiner D. The Use of Goal Attainment Scaling in a Geriatric Care Setting. J Am Geriatr Soc. 1992; 40: 574-578. 
20. Stolee P, Stadnyk K, Myers A, Rockwood K. An Individualised Approach to Outcome Measurement in Geriatric Rehabilitation. J Gerontol Ser A. 1999; 54 (12): M641-M647.

21. Yip A, Gorman M, Stadnyk K, Mills W, MacPherson K, Rockwood K. A Standardised Menu for Goal Attainment Scaling in the Care of Frail Elders. Gerontologist. 1998; 38 (6): 735-742.

22. Gordon J, Powell C, Rockwood K. Goal Attainment Scaling as a Measure of Clinically Important Change in Nursing-home patients. Age Ageing. 1999; 28: 275281.

23. Bravo G, Dubois M-F, Roy P-M. Using goal attainment scaling to improve the quality of long-term care: a group-randomised trial. Int J Qual Health C. 2005; 17 (6): 511-519.

24. Rockwood K, Fay S, Song X, MacKnight C, Gorman M. Attainment of Treatment Goals by people with Alzheimer's Disease receiving Galantamine: A Randomised Controlled Trial. CMAJ. 2006; 174 (8): 1099-1105.

25. Bouwens S, van Heugten C, Verhey F. The practical use of goal attainment scaling for people with acquired brain injury who receive cognitive rehabilitation. Clin Rehabil. 2009; 23: 310-320. 
26. Wilz G, Schinkothe D, Soellner R. Goal attainment and treatment compliance in a cognitive-behavioral telephone intervention for Family Caregivers of persons with dementia. GeroPsych. 2011; 24 (3): 115-125.

27. Kiresuk T, Lund S. Implementing Goal Attainment Scaling, in Kiresuk T, Smith A, Cardillo J. (eds.) Goal Attainment Scaling: Applications, Theory, and Measurement. New Jersey: Lawrence Erlbaum Associates Publishers; 1994.

28. Clare L, Kudlicka A, Oyebode JR, Jones RW, Bayer A, Leroi I, Kopelman M, James IA, Culverwell A, Pool J, Brand A, Henderson C, Hoare Z, Knapp M, Woods B. Individual goal-oriented cognitive rehabilitation to improve everyday functioning for people with early-stage dementia: A multicentre randomised controlled trial (the GREAT trial). Int J Geriatr Psychiatry. 2019; 34(5): 709-721.

29. Chester H, Clarkson P, Davies L, Hughes J, Islam MS, Kapur N, Orrell M, Peconi J, Pitts R, Poland F, Russell I, Challis D, Members of the HoSt-D (Home Support in Dementia) Programme Management Group. Cognitive aids for people with early stage dementia versus treatment as usual (Dementia Early Stage Cognitive Aids New Trial [DESCANT]): study protocol for a randomised controlled trial. Trials. 2018; 19 (546): $1-11$.

30. Chester H, Beresford R, Clarkson P, Entwistle C, Gillan V, Hughes J, Orrell M, Pitts R, Russell I, Symonds E, Challis D, Members of the HoSt-D (Home Support in Dementia) Programme Management Group. Implementing the Dementia Early Stage 
Cognitive Aids New Trial (DESCANT) intervention: mixed-method process evaluation alongside a pragmatic randomised trial. Aging Ment Health; submitted.

31. Chester H, Clarkson P, Kapur N, Challis D, Orrell M, Ainsworth C, Ledgerd R, Pimlott B, Spector A, Woods B. Using memory aids in early-stage dementia: a pragmatic randomised trial - Intervention manual. Manchester: PSSRU, University of Manchester; 2017.

32. Moore GF, Audrey S, Barker M, Bond L, Bonell C, Hardeman W, Moore L, O'Cathain A, Tinati T, Wight D, Bair, J. Process evaluation of complex interventions: Medical Research Council guidance. BMJ. 2015; 350: h1258.

33. Molloy D, Standish T. Mental status and neuropsychological assessment: a guide to the Standardised Mini-Mental State Examination. Int Psychogeriatr. 1997; 9: 8794.

34. Braun V, Clarke V. Using thematic analysis in psychology. Qual Res Psychol. 2006; 3(2): 77-101.

35. Giebel CM, Challis D, Montaldi D. A Revised Interview for Deterioration in Daily activities in Dementia (R-IDDD) reveals the relationship between social activities and well-being. Dementia. 2016; 15 (5): 1068-81. 
36. Bucks RS, Ashworth DL, Wilcock GK, Siegfried K. Assessment of activities of daily living in dementia: development of the Bristol Activities of Daily Living Scale. Age Ageing. 1996; 25:113-20.

37. Katz S, Ford AB, Moskowitz RW, Jackson BA, Jaffe MW. Studies of illness in the aged. The index of ADL: A standardized measure of biological and psychosocial function. JAMA. 1963; 185: 914-919.

38. Berwig M, Heinrich S, Spahlholz J, Hallensleben N, Brahler E, Gertz H-J. Individualized support for informal caregivers of people with dementia - effectiveness of the German adaptation of REACH II. BMC Geriatr. 2017; 17(1): 286.

39. Chien W, Lee I. Randomised controlled trial of a dementia care programme for families of home-resided older people with dementia. J Adv Nurs. 2001; 67(4): 774787.

40. Dias A, Dewey M, D'Souza J, Dhume R, Motghare D, Shaji K, Menon R, Prince $M$, Patel V. The effectiveness of a home care program for supporting caregivers of persons with dementia in developing countries: a randomised controlled trial from Goa, India. PLoS One; 2008; 3(6): e2333. doi: 10.1371/journal.pone.0002333.

41. Livingston G, Barber J, Rapaport P, Knapp M, Griffin M, King D, Romeo R, Livingston D, Mummery C, Walker Z, Hoe J, Cooper C. Long-term clinical and costeffectiveness of psychological intervention for family carers of people with dementia: a single-blind, randomised, controlled trial. Lancet Psychiat. 2014; 1(7): 539-548. 
42. de Oliveira AM, Radanovic M, de Mello PC, Buchain PC, Vizzotto ADB, Celestino DL, Stella F, Piersol CV, Forlenza OV. Nonpharmacological Interventions to Reduce Behavioral and Psychological Symptoms of Dementia: A Systematic Review. BioMed Res Int. 2015; 2015: 218980.

43. Nordheim J, Hausler A, Yasar S, Suhr R, Kuhlmey A, Rapp M, Gellert P. Psychosocial intervention in couples coping with dementia led by a psychotherapist and a social worker: the DYADEM trial. J Alzheimer's Dis. 2019; 68 (2): 745-755.

44. Oyebode J, Parveen S. Psychosocial interventions for people with dementia: an overview and commentary on recent developments. Dementia. 2016; 18 (1), 8-35.

45. Audrey S, Holliday J, Parry-Langdon N, Campbell R. Meeting the challenges of implementing process evaluation within randomised controlled trials: the example of ASSIST (A Stop Smoking In Schools Trial). Health Educ Res. 2006; 21 (2): 366-377.

46. Bowling A. Research methods in health: investigating health and health service, third edition. Berkshire: Open University Press; 2009.

47. Mowbray C, Holter M, Teague G, Bybee D. Fidelity criteria: development, measurement, and validation. Am J Eval. 2003; 24 (3): 315-340.

48. Ruble L, McGrew JH, Toland MD. Goal attainment scaling as an outcome measure in randomized controlled trials of psychosocial interventions in autism. J Autism Dev Disord. 2012; 42(9): 1974-1983. 
49. Challis D, Sutcliffe C, Hughes J, von Abendorff R, Brown P, Chesterman J. Supporting People with Dementia at Home: Challenges and Opportunities for the 21st Century. Oxon: Routledge; 2016.

50. Public Health England. Guidance: Process Evaluation. https://www.gov.uk/government/publications/evaluation-in-health-and-well-beingoverview/process-evaluation. Accessed October 4, 2019.

51. Bogardus S, Bradley E, Tinetti M. A taxonomy for goal setting in the care of persons with dementia. J Gen Intern Med. 1998;13: 675-680.

52. Wells Fargo. Data in high fidelity https://global.wellsfargobank.com/wfinsightsarticles-data-in-high-fidelity-thought-leadership?elqTrack=true. Accessed March 17, 2020. 
